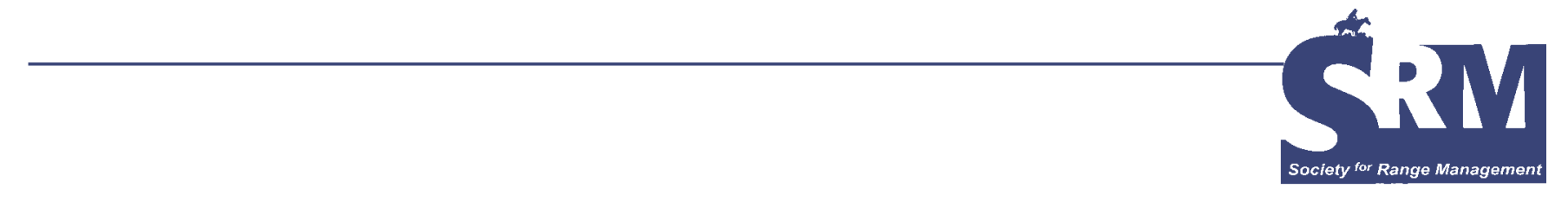

\title{
2008 SRM High School Youth Forum Paper Presentations
}

\section{Barron S. Rector, SRM HSYF Sub-Committee Co-Chair, Abstracts by HSYF Authors}

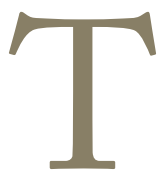

he High School Youth Forum (HSYF) program began in 1966 at the Salt Lake City Annual Meeting as the Youth Range Forum. High school-age delegates are selected for participation in the Forum by the Sections of the Society based on their interest, achievements, and activities in range and natural resource management at the Section level. Beginning in the early 1970s, the program format began to encourage youth thought and enhancement of communication skills. A taste of what range professionals do was achieved by asking each Forum delegate to prepare a six- to eightminute formal presentation on a range-related topic. The HSYF paper presentation session today is treated similarly to other formal educational annual meeting sessions, except that it is a competition. In the late 1980s, the top two to three winning papers began to be published in Rangelands. For our Section-sponsored youth, this effort has brought about a true educational process. These youth select a topic by visiting and working with Society members, research an idea, prepare a written paper, and then present the main ideas of the paper in a formal speaking presentation. The Forum delegates most often continue to use their presentation in other youth competitions, as speakers at various summer camps and local organization meetings, and serve as ambassadors in their states or Sections for range stewardship.

FIRST PLACE: Erica David, Wyoming Section, The "Hollow Frame Fence"-Year 7: Investigations of Innovative Snow Fence Designs to Maximize Snow Capture for Water Conservation in Reclamation in Industrial Settings. Snow fences are traditionally studied for protection from blowing

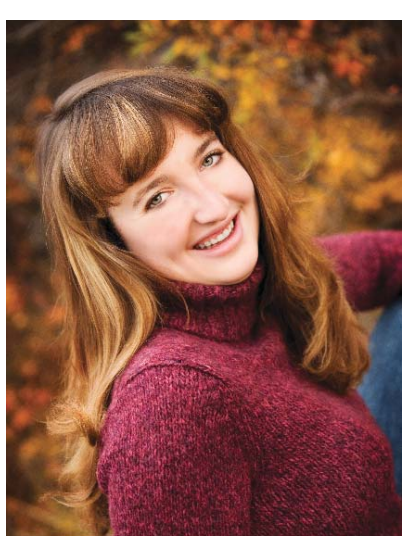

and drifting snow. However, little research exists on using snow fences to restore disturbed habitat. This study developed the potential to use snow as a viable water supply to improve growth of important native vegetation. Analysis of snowdrift characteristics, soil moisture, and vegetation growth developed the most effective snow fence system for habitat restoration. By compiling links between snow fencing and reclamation success, this study investigates industrial potential to reclaim disturbed land, enhancing fence efficiency and economic viability. The ultimate goal is implementation of snow fence systems as a standard reclamation tactic.

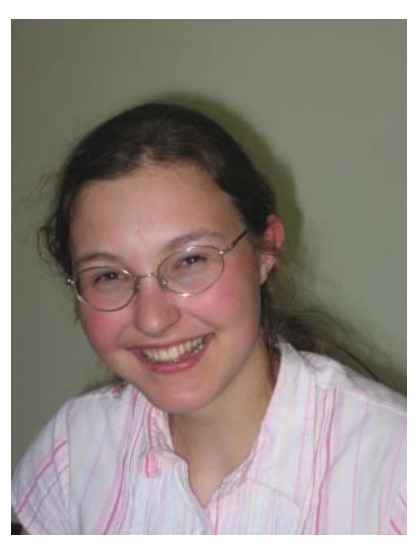

SECOND PLACE: Ruby Ann Steigelmeier, South Dakota Section, Leafy Spurge: We're Not Letting It Grow On Us. Leafy spurge, a South Dakota statewide noxious weed, has infested 317,000 acres in the state as of 2007 , and costs landowners $\$ 14,000,000$ per year in lost grazing units. After finding an acre of spurge in our pasture, we took immediate 
action to prevent its spread. Because our ranch is certified organic, we chose to mow and use biocontrol agents. The flea beetles and mowing made the plants yellow and sickly. Our sheep selected the spurge leaves and stripped the plants. In two years we have seen a reduction in leafy spurge plant health and density.

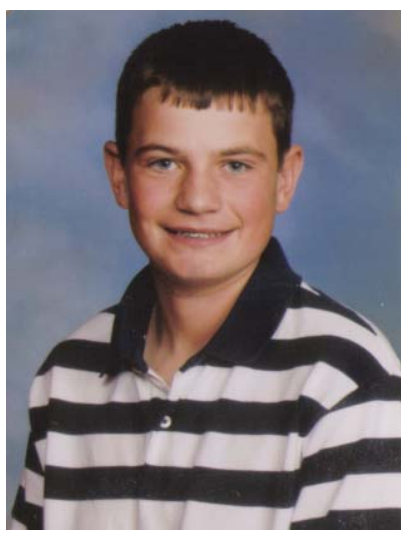

THIRD PLACE: Jake Nelson, Nebraska Section, Five Generations of Conservation. I am a 5 th generation rancher. My paper focuses on the past, present, and future of my family's rangeland. From the freeroaming Native Americans to the current generation of tractors and combines, my paper examines how range management practices have changed over time. It also illustrates the range management methods my family has used over the past five generations and the special problems I face today. The main purpose of this paper was to highlight that my range management goals include educating myself so I can make the best decisions for my family's pastures and farmland.

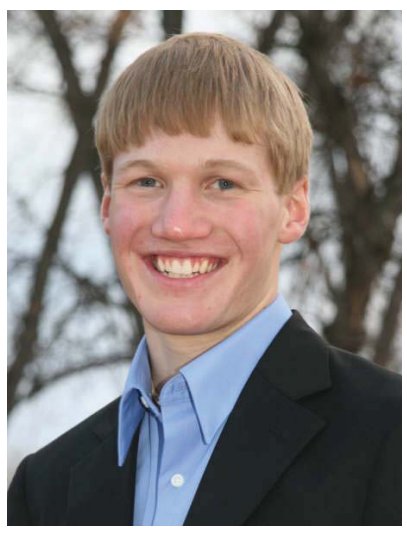

FOURTH PLACE: Daniel Pratt, Northern Great Plains Section, The New Battle for the Bighorn. Salt cedar, a shrub native to Asia, has become a prevalent invader in Montana's riparian ecosystems. The plant's physiology makes it a threat in any environment and it takes a devastating toll on native plant communities. Currently, land managers are combating salt cedar using a combination of mechanical, chemical, and biological controls. As a problem that can never be eradicated, vigilant management practices are required to control salt cedar infestations.

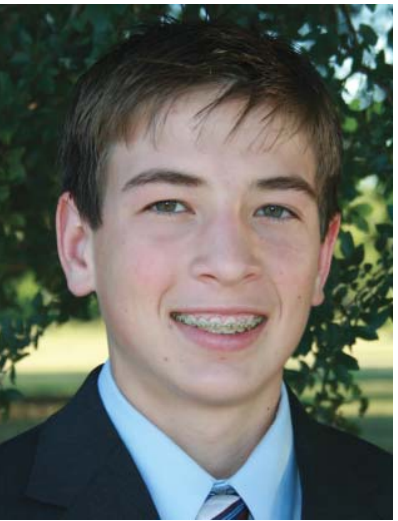

FIFTH PLACE (Tie): William Cohen, Texas Section, Wildlife Management is Pointless? Range wildlife and plant diversity are declining. Thousands of species have been threatened with extinction. Many range experts have focused on the proximate causes of wildlife decline, rather than the root cause: human population growth. Human population is and will continue to increase, and consumption will continue to impact range wildlife, thwarting any attempt to save them. Therefore wildlife management is pointless unless conservationists and range managers first address the problem of population growth. Earth is a unique planet in our galaxy and we must take steps to prevent damage to its inhabitants.

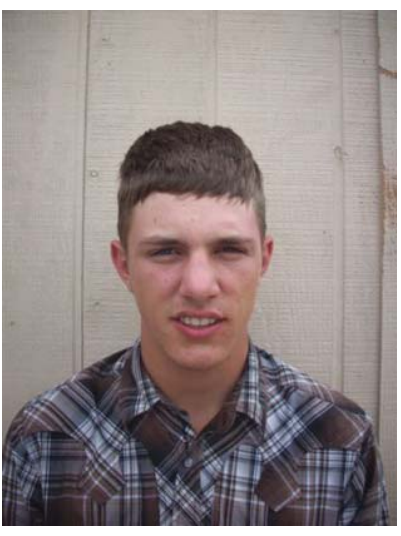

FIFTH PLACE (Tie): Jade Meinzer, Colorado Section, From Litter to Llamas: Managing Sub-AlpineRangelands. Grazing tests performed at the Rocky Mountain Mennonite Camp near Divide, Colorado (elevation 9600 feet) revealed greater diversity among plant species and an increase in palatable plant production within a properly grazed range over that of an over-rested range. Four llamas were used as the variable to graze six three-tenths-acre paddocks. The llamas were grazed for a period of 28 days, which was determined by dividing total production of the rangeland by the total daily intake of a llama. Test data revealed that controlled grazing is beneficial to rangelands.

Editor's Note: This special report on SRM's youth was edited and compiled by Rangelands Associate Editor Kim McReynolds. Each student's paper can be read online at www.rangelands. org/HSYForum/index.shtml. 